\title{
Original Research Article \\ Analysis on the Protection Strategy of Intangible Cultural Heritage in Contemporary China
}

\author{
Liu Zhou ${ }^{1}$ \\ Jiangxi Institute of Fashion, Jiangxi, 330201
}

\begin{abstract}
Intangible cultural heritage is a form of custom and cultural ideology retained by the people of all ethnic groups in the world, which is closely related to their daily life. Its inheritance and development are of inexpressible significance and inestimable value to the whole human civilization. This paper focused on the principles that should be followed in the protection of intangible cultural heritage projects in China, analyzed the key points and difficulties in the implementation of each principle, then analyzed and discussed the strategies for the protection of intangible cultural heritage projects from different angles. Through these ways, this paper expected to play an important role in protecting and inheriting a variety of non-heritage projects in our country, so as to show its exuberant vitality in modern life.
\end{abstract}

Keywords: Intangible Cultural Heritage; Principle; Strategic Analysis

Since entering the modern society, the world economy has developed rapidly, and the level of productive forces is changing with each passing day. The economic globalization and multi-angle cultural exchanges brought about by the network environment have had a strong impact and stimulation on the traditional way of life. Today, when foreign cultures are integrated into our daily life, the change of people's way of life is extremely obvious. The ideological framework of traditional culture has been on the verge of collapse, while the intangible cultural heritage, which has lasted until now, exists with a specific historical background and social environment. It is hidden in the social environment, sacrificial activities and daily social activities. The change of public ideas and the new needs of life make the intangible cultural heritage more likely to be destroyed and wiped out. Therefore, how to protect and inherit the connotation of these heritage has become an important problem to be solved urgently.

On October 17, 2003, UNESCO specially issued the Convention for the Safeguarding of the Intangible Cultural Heritage (hereinafter referred to as the Protection Convention) for countries to implement protection strategies according to their own special circumstances. The Chinese government also responded positively to the formal launch of the declaration of the "intangible cultural heritage" protection project in 2005, and the provincial, municipal and county governments and non-governmental organizations responded to the call to sort out the census, raise funds, and foster development. However, due to the lack of experience, there is obvious blindness, one-sidedness and utilitarianism in the process of emergency rescue and arrangement. The author personally participated in such activities during his graduate school. In the process of collection and declaration at the county and city level, due to the limitations of villagers' knowledge and insufficient publicity by relevant government departments, there are a large number of repeated projects, and daily life utensils, recipe menus, local songs and dances are also included in the declaration, which brings huge classification troubles to cultural managers, wastes human, material and mental resources, and causes new damage and losses to many non-heritage projects that are already on the verge of being lost. The existence of these problems must be solved in time. Moreover, the intangible cultural heritage also has the characteristics of activity, nationality, inheritance, regionality, diversity, collectivity, variability and so on. These characteristics also determine that the mode of protection and development of intangible cultural heritage must be diverse and three-dimensional full coverage.

As we all know, the fundamental reason for the protection of intangible cultural heritage is to enable it to adapt to today's social development process, reduce its damage caused by culture shock, and continue to pass it on. At present, the academic circles have two views on how to protect the non-heritage project: one is to think about the non-heritage object as an independent individual, and the limitation of "protection" is understood as the concrete preservation and maintenance of this unique individual. The specific forms of protection of this idea are as follows: local repair, remote relocation, enclosure and other common measures.

1 About the author: Liu Zhou (1989-), male, Han nationality, native of Yancheng, Jiangsu Province. Teacher and lecturer of Jiangxi Garment Institute. Master's degree, major: design, research direction: visual communication design. Mailing address: Jiangxi Garment Institute, Lihu Avenue, Nanchang County, Nanchang City, Jiangxi Province. To: Liu Zhou, Tel: 18551843205.

This is an open-access article distributed under the terms of the Creative Commons Attribution Non-Commercial License

(http://creativecommons.org/licenses/by-nc/4.0/), which permits unrestricted non-commercial use, distribution, and reproduction in any medium, provided the original work is properly cited. 
The final result is that the intangible heritage projects, which were originally close to the lives of the people and are ever-changing, are stripped out from people's lives and become historical products of "solidification" and "stillness", setting up shackles around them and making them lose their own vitality. Another view was put forward by UNESCO, which clearly states in the Protection Convention that the so-called "protection" refers to the adoption of measures to ensure the viability of the intangible cultural heritage, including the recognition, documentation, research, preservation, protection, promotion, promotion, inheritance (mainly through formal and non-formal education) and revitalization of all aspects of such heritage. "This point of view has a correct grasp of the definition and characteristics of the intangible cultural heritage and treats the intangible project as a living and ever-changing living existence. At the same time, the view holds that the essence of "protection" is not only to maintain and maintain its existing vitality, but also to make it have the ability of "sustainable development" according to the social characteristics of the times. This is also the view that our country has been adhering to for the protection of non-heritage, and it is the survival way that a large number of non-heritage projects in our country can continue and still be able to shine in the future.

To achieve this goal, we need to follow the following basic principles:

\section{The principle of authenticity.}

In 1964, the Venice Charter established the significance of authenticity to the protection of modern international heritage, proposing that "it is our responsibility to pass on cultural heritage truly and completely", which is also the basic principle that we follow in the protection of intangible heritage projects. When we collect and sort out the intangible cultural heritage, we should put forward requirements for integrity from four aspects: design, materials, craftsmanship and environment. When we protect the intangible cultural heritage project, we should not only consider the project itself, but also need to protect its ecological environment, so as to ensure the integration and unity of the external expression and the internal cultural significance of the intangible cultural heritage.

\section{The principle of adaptation and innovation.}

The intangible cultural heritage of our country is the crystallization of our ancestors' hard work and wisdom, and it is a treasure house containing great humanistic value. After years of vicissitudes and changes of events, it can still play a role today, so our protection today must follow the principle of adaptation and innovation. At present, the correct protection method is to meet the needs of the times, innovate product types and strengthen the market adaptability of non-heritage projects. In the face of the new living environment, intangible cultural heritage projects need to spit out the old and accept the new, integrate innovation and selfadjustment, so as to form a new form with the unity of traditional values and modern ideas. This idea of actively seeking innovation is an important inspiration that the non-heritage project can meet the needs of the society, push through the old and bring forth the new, and multiply endlessly. Throughout the history of the development of human civilization, what plays an important role is the creativity of human beings in pursuit of a better life and improvement of production tools. Therefore, in order to ensure the lasting vitality of the intangible cultural heritage project, the most important thing is to stimulate its ability to adapt and innovate.

\section{The principle of education}

The protection of non-heritage projects is a common matter of the whole society, which requires the efforts of our generations. This requires us to pass on the importance of protecting the intangible cultural heritage to the young people, so as to enhance the protection consciousness of the whole nation, form a strong social public opinion and moral standard, and integrate the consciousness of protection into people's daily life. Rooted in the mind. At the same time, another important purpose of bringing non-heritage protection into education is to strengthen the training of professional scientific research personnel and strive to improve their theoretical knowledge, skills and methods. In the long run, in the whole education system, popularizing culture and improving the level of professional skills promote each other and form a virtuous circle of a complete chain. Nowadays, non-heritage majors or related cultural and theoretical disciplines have been set up in many colleges and universities. At the same time, design majors are also making use of the decorative patterns, carrier expression, cultural connotation and so on of non-heritage projects to carry out innovative product development. All these can promote the protection of intangible cultural heritage to enhance their strengths and circumvent their weaknesses in practice and move towards science and perfection. If we can firmly implement these protection principles and increase the intensity of protection, then in the near future, non-heritage projects are expected to continue to develop and form new non-heritage projects in the next era on the basis of integrating the needs of contemporary ideas.

\section{The principle of unity}

Chinese culture is composed of multi-ethnic cultures, and many minority cultures have been annihilated in the long river of history in the process of development. However, the culture of every nation is a classic and an indispensable part of our spiritual culture, and each of their non-heritage projects is also a valuable source of innovation for us today. We cannot simply judge which kind of non-heritage project is more valuable, more meaningful or more necessary for inheritance and development than another kind of non-heritage project. To this end, we need to go hand in hand in the protection, development and utilization of non-heritage projects, make common progress, and not favor one over the other, so as to have an impact on the process of intangible cultural protection in our country.

Through the discussion of the above four principles of non-heritage protection, it can be found that the protection of nonheritage projects requires the active coordination and cooperation of all sectors of society. So, what roles do different functional departments play in it? The author believes that it should be divided into two parts, including the main body of civil power of the cultural inheritors of civil society and the object of auxiliary propaganda forces (including the government, academia, business circles, news media and cultural security organizations at all levels). Without the participation of folk forces, how can we sum up the survival law of the continuation of traditional folk culture? How do researchers carry out theoretical exploration from 
the perspective of folk thinking, and then carry out implementation and practice by following examples? Of course, this does not require us to do nothing about the protection of the intangible cultural heritage. If we really govern by doing nothing, the consequence must be that the protection of intangible cultural heritage will come into a dead corner, and at the same time, it will be bumpy for the revival of traditional culture. Therefore, we can learn from the experience and theory summed up in the development of folklore, carry out research work from the perspective of civil society, follow the law of natural evolution of traditional cultural changes, and reduce the damage to the original connotation of culture. Of course, the object of propaganda is also essential. Without the active organization, mobilization and guidance of governments at all levels, scholars' in-depth non-governmental investigation activities will be difficult to move forward, without the extensive publicity of media power, and folk forces know little about the importance of non-heritage projects, with the passage of time, more and more non-heritage species will disappear. Only when the two integrate and complement each other, give full play to the independent initiative of the subject and the external assistance of the object, can we retain the original nature of folk culture to the greatest extent and achieve the effect of getting twice the result with half the effort.

To sum up, we can see that the protection of intangible cultural heritage projects play a very important role in the continuous development of our country's culture. The protection of intangible cultural heritage projects is in line with the requirements of China's cultural development for economic benefits, sustainable development and system development, and can alleviate the inadaptability brought about by the current cultural integration and transformation in our country. In the era of global economic integration, the desire for the development of modern cultural industry is beyond expression. We need to pay more attention to the protection and inheritance of our national traditional culture, which is the source of our development, the national cultural totem that we can show, and the solid foundation that our culture can continue to stand in the forest of world culture. Therefore, it is of great significance to inherit and develop intangible cultural heritage projects and create brands with national characteristics, which is of great significance to enhance China's foreign cultural output and international influence.

\section{References}

1 Guo Wanping. World Natural and Cultural Heritage [M]. Hangzhou: Zhejiang University Press, 2006.

2 Lv Qinghua. Industrial development of cultural resources [M]. Beijing: economic Daily Press, 2006.

3 Mou Yanlin. Intangible cultural heritage: how to protect it? [J]. Journal of Chongqing University of Arts and Sciences, 2006 (2): 2-4.

4 Dai Lian. The Perplexity of Intangible Cultural Heritage Protection, Outlook Newsweek, No. 30, 2005. 